\title{
The influence of social capital and socio-economic conditions on self-rated health among residents of an economically and health-deprived South African township
}

\author{
Jane M Cramm ${ }^{*}$ and Anna P Nieboer
}

\begin{abstract}
Background: Surprisingly few studies have investigated the interplay of multiple factors affecting self-rated health outcomes and the role of social capital on health in developing countries, a prerequisite to strengthening our understanding of the influence of social and economic conditions on health and the most effective aid. Our study aimed to identify social and economic conditions for health among residents of an economically and healthdeprived community.

Methods: Data were gathered through a survey administered to respondents from 1,020 households in Grahamstown a suburb in the Eastern Cape, South Africa (response rate 97.9\%). We investigated the influence of social and economic conditions (education, employment, income, social capital, housing quality and neighborhood quality) on self-rated health. We used ordinal logistic regression analyses to identify the relationship of these conditions and self-rated health.

Results: Our study found that education and social capital positively correlated with health; unemployment, poor educational level and advanced age negatively correlated. We found no significant correlations between self-rated health and housing quality, neighbourhood quality, income, gender, or marital status.

Conclusion: We highlight the possible impacts of social capital, employment, and education on health, and suggest that health outcomes may be improved through interventions beyond the health system: creating job opportunities, strengthening social capital, bettering educational systems, and promoting educational access. Policymakers should consider the benefits of such programmes when addressing health outcomes in financially distressed districts.
\end{abstract}

Keywords: social capital, social determinants, socioeconomic status, health status, South Africa

\section{Background}

People at the bottom of society are faced with the worst living conditions and report the worst health outcomes. Regardless the country these poor people live in, what type of health insurance they have or do not have, and the level of health care they receive, they still have the worst health of all [1]. These disparities cannot be explained by biological differences. The World Health Organization [2] holistically viewed the social determinants of health, concluding that global health and illness

\footnotetext{
* Correspondence: cramm@bmg.eur.nl

Institute of Health Policy and Management, Erasmus University Rotterdam, P. O. Box 1738, 3000 DR Rotterdam, the Netherlands
}

follow a social gradient; lower socioeconomic positions are consistently correlated with poorer health. These avoidable health inequalities arise because of the circumstances in which people are born, live, work, and age, including the adequacy of health care systems. The conditions in which people live and die are, in turn, shaped by social and economic forces. Together, the structural determinants and conditions of daily life constitute the socioeconomic determinants of health [3]. Research has shown that, despite the potential of the health system in developing countries in reducing socioeconomic inequality, such inequality is related to factors beyond the scope of health authorities and the health care delivery system 
$[4,5]$. Therefore, health systems will not be able to achieve equity without commitments and interventions beyond the health sector [6-10].

Overcoming health inequity requires evidence based on measurement of the social determinants of health [11]. The act of measurement itself is a challenge as the poor are often missing from official statistics [12]. To strengthen our understanding of health inequity, the social determinants of health, and the most effective means of improvement, studies must be conducted in economically and health-deprived communities [13-15].

Evidence suggests that individual socioeconomic resources (education, employment and income) affect health [15-20]. In addition, individual level experiences of environmental conditions such as housing quality (e.g. leaking roof) and neighborhood quality may affect individual health [16-20]. Neighbourhood crime is an example of neighbourhood quality representing residents' perceived threat to personal safety and environmental stress [20]. A growing body of evidence has demonstrated that higher social capital is associated with improved health conditions [21-25]. Putnam referred to social capital as, 'features of social organization such as networks, norms, and social trust that facilitate coordination and cooperation for mutual benefit' [26]. While social capital is recognised to have an important influence on health, the specific mechanisms of this association remain incompletely defined. Researchers have suggested three possible mechanisms to explain how social capital produces health benefits: (1) influence health-related behaviors, (2) influence access to services and amenities and (3) affect psychosocial processes [26,27]. Rogers' diffusion of innovations theory [28] suggests that social capital may promote the diffusion of health-related knowledge and interventions within communities and neighbourhoods. Because social capital reflects the social processes, norms, and trust among community members, it is an important resource for community health promotion. Social capital can provide valuable, up-to-date, and timely health information and promotes the diffusion of health-related interventions [27]. The success of community interventions often lies in their ability to engage and strengthen social capital. They are grounded in the notion that healthy behaviour is better shaped by influencing social norms and negotiating collective identities, rather than providing individuals with factual information. This theory is supported by research demonstrating that health behavior is influenced more by perceptions than knowledge [29-32]. Individuals obtain health information primarily through social connections [33], and communities with high levels of social capital are more effectively in exercising social control over health behaviours [27]. Poortinga [34] demonstrated that social capital is an important determinant of health and healthy behaviour, and suggested that healthy behaviours mediate the relationship between social capital and health. In addition, social capital may affect psychological processes, including the provision of affective support and mutual respect [35], that may discourage deviant health behaviours [34]. Furthermore, it may shelter people from the harmful effects of unemployment and poverty $[35,36]$, or provide a buffer against the adverse effects of stress and poverty [37].

\section{Study aims}

Many studies investigated the relationship between socio-economic conditions and health outcomes. Few studies, however, investigated the role of social capital as a socio-economic condition on health. Although there are some studies that have tested the relationship between social capital and health, they all have one major limitation: poor people or those within deviant or marginalized communities have been excluded [38]. Our study aimed to identify the role of social capital in addition to other well-known socio-economic conditions (education, employment, income, housing quality and neighborhood quality) on health for residents of an economically and health-deprived community in South Africa. We hypothesize that social capital affects health among poor communities.

\section{Methods}

\section{Participants and sampling}

South Africa's historical pattern of racially segregated spatial planning may have led to poor health and created different health patterns. Rhini is characterised by high levels of poverty and unemployment and low educational levels $[39,40]$. The survey forming the foundation of our study covered the informal residential areas within the Grahamstown municipal district, referred to as Grahamstown East, or Rhini. A systematic sampling technique was employed to sample the 11,127 households in the 2,500 square kilometres of Rhini [41]. Public structures such as civic offices, schools, and churches were omitted. All neighbourhoods in the sample were proportionately represented in the study population. Sampling began from a randomly chosen point and moved systematically through each of the 20 neighbourhoods. Every tenth household was selected for inclusion in the sample, resulting in 1,042 targeted households. This method ensured that all households in all neighbourhoods of Rhini stood an equal chance of inclusion.

Respondents were then identified in each targeted household. Eligibility requirements were age (at least 18) and length of residency (at least 6 months of the past year). One respondent from each targeted household was selected using a Kish grid to ensure that all eligible persons in the household stood an equal chance of being included [42]. Up to four attempts were made to interview the selected respondents, with success in 1,020 
(97.9\%) of the 1,042 households. In the remaining cases, respondents were absent for all four visits, impaired by age or health, or disinterested/unwilling.

\section{Survey instrument}

Professional interviewers from Development Research Africa, an organisation with experience in national probability-based sampling in deep rural and urban areas, administered the questionnaires in 2007. Most items were closed-ended, with a supplied set of response options. The interviewers gathered demographic information about the participants, including gender, age, health status, education level, living arrangements, and employment.

\section{Measurements}

Health status, however measured, is more than just the absence of disease. It includes a set of factors that relate to how individuals feel as well as function in society and the environment [43]. We determined self-reported health status with the question, "How would you describe your overall state of health these days? Would you say it is (4) excellent, (3) very good, (2) good, (1) fair, or (0) poor?" thus defining it as the individual's personal evaluation of their overall health without referring to any one component of physical, social, mental, or functional health. Public health research has typically used this measure as a proxy for "objective" but difficult to measure health outcomes. The test-retest reliability of self-rated health has been shown to be high across subgroups of age and sex [44].

To investigate socio-economic conditions affecting health, the questionnaire established employment, household income (ranging from (1) between 0 and 100 South African Rand to (13) more than 7,000 South African Rand), age, gender, marital status, and education, the last having the answers: "no education", "some primary and/or secondary education", "matric and higher education".

Following Putnam, we measured social capital through respondents' perceptions of the norms of reciprocity and their trust in others, factors that facilitate cooperation for mutual benefit [26]. Social capital was assessed with three statements for which respondents rated their level of agreement on a four-point scale: "People in this neighbourhood are friendly", "people in this neighbourhood help each other without having to be asked", and "people in this neighbourhood trust their neighbours". Social capital scores are derived by summing the response choices on these three items and dividing it by the corresponding number of items. The Cronbach's alpha of the social capital instrument was 0.87 , indicating reliability.

We assessed housing quality with a dichotomised item, "Has the roof leaked in the past year?' and by asking respondents to identify whether their house is built formally (brick/cement block) or informally (shack/ traditional pole/mud house), to which they could answer 'yes', or 'no'.

Neighbourhood quality was estimated with two survey items: "Residents in this neighbourhood get fair values for their rental rates" and "There is not a lot of crime in this neighbourhood". Respondents rated their level of agreement to both neighbourhood quality survey items on a four-point scale.

\section{Data analysis}

We generated descriptive summary statistics and performed regression analyses to identify social and economic conditions (education, employment, income, social capital, housing quality and neighborhood quality) for residents of an economically and health-deprived community in South Africa. We applied an ordinal logistic regression model to account for the ordinal structure of the outcome variable. We defined the level of significance at $P \leq 0.05$; we additionally report results with a larger level of confidence $(P \leq 0.001)$. The regression equation specification error test will be used to detect if our model is misspecified. Statistical Package for the Social Sciences (SPSS) version 17.0 software was used for all statistical analyses.

\section{Results}

Respondents were mostly female (73\%), had a median age of 38 (range: 18-98), and in one-third (33\%) of the cases, were married. Thirty-five percent had no formal schooling or only primary education, $40 \%$ some secondary education, and $25 \%$ had matriculated or had higher education. One-half (50\%) of respondents had had a roof leak in the past year; $72 \%$ lived in a formal house and $28 \%$ in an informal house (shack or mud dwelling). Table 1 provides descriptive statistics for the variables used in the ordinal logistic regression analyses.

Table 2 presents the results of the ordinal logistic regression analyses on self-rated health. These analyses revealed that unemployment, poor educational level and increasing age significantly contributed to poor health status within this community, while social capital significantly promoted good health. No significant correlations were found between self-rated health and housing type, leaky roof, neighbourhood quality, income, gender, or marital status (table 2). The OR for employment was 2.058 , indicating that the ratio of the odds for good health increased by 2.058-fold for the employed compared to the unemployed, assuming all other factors in the model remained constant. Having non or only some primary education decreased the odds of good health by factor 0.464 compared to those with higher educational levels (matric or higher). Similarly, an increase in age was related to a decrease in the odds for good health by a factor 0.942 . Higher levels of social capital was related 
Table 1 Descriptive statistics ( $n=1,020$; Grahamstown 2007)

\begin{tabular}{|c|c|c|c|c|c|c|}
\hline Model & $\mathrm{N}$ & $\%$ & Mean & SD & Min & Max \\
\hline Health & & & 2.55 & 1.01 & 0.00 & 4.00 \\
\hline 0 (poor) & 17 & $2 \%$ & & & & \\
\hline 1 (fair) & 156 & $17 \%$ & & & & \\
\hline 2 (good) & 214 & $23 \%$ & & & & \\
\hline 3 (very good) & 405 & $43 \%$ & & & & \\
\hline 4 (excellent) & 143 & $15 \%$ & & & & \\
\hline \multicolumn{7}{|l|}{ Socio-economic conditions/resources } \\
\hline Married & 304 & $33 \%$ & & & & \\
\hline Male & 249 & $27 \%$ & & & & \\
\hline Unemployment & 579 & $62 \%$ & & & & \\
\hline \multicolumn{7}{|l|}{ Education } \\
\hline None or some primary & 325 & $35 \%$ & & & & \\
\hline Some secondary & 375 & $40 \%$ & & & & \\
\hline Matric or higher & 235 & $25 \%$ & & & & \\
\hline Income & & & 1,250 & 2.13 & 0.00 & $>7,001$ \\
\hline Social capital & & & 2.97 & 0.54 & 1.00 & 4.00 \\
\hline \multicolumn{7}{|l|}{ Housing quality } \\
\hline Leaky roof & 471 & $50 \%$ & & & & \\
\hline Formally build house & 670 & $62 \%$ & & & & \\
\hline \multicolumn{7}{|l|}{ Neighbourhood quality } \\
\hline Crime in the area & & & 2.03 & 0.89 & 1.00 & 4.00 \\
\hline Residents get value for their rental rates & & & 2.19 & 0.74 & 1.00 & 4.00 \\
\hline
\end{tabular}

to an increased probability of good health, as indicated by a 1.650 OR, meaning that the odds for good health increased by factor 1.650 for community members with higher levels of social capital, assuming all other factors in the model remained constant. This model explained $35.3 \%$ of the variance in the outcome measure (as indicated by Nagelkerke's $R^{2}$ ). The regression equation specification error test showed that our regressions model is not misspecified.

\section{Discussion}

Our study aimed to identify the social and economic condition affecting health among residents of Rhini, an economically and health-deprived community in the Eastern Cape of South Africa. We hypothesized that in addition to well-known socio-economic conditions, social capital affects health among poor communities. As expected, our study showed that social capital affected health in poor communities. Our study corroborates the importance of social capital. Social capital may have promoted the diffusion of health-related knowledge, since people obtain much of their health information through social connections [33]. Higher levels of social capital may therefore have led to increased knowledge, as well as healthy and disease-preventive behaviours. These results agree with Poortinga [34] identifying that social capital is an important determinant of health and healthy behaviour, and suggested that healthy behaviours mediate the relationship between social capital and health. Lack of social capital may lead to increased feelings of loneliness and stress, which negatively affect health outcomes and lead unhealthy behaviours such as drinking and smoking. Furthermore, social capital can affect psychological processes like support and mutual respect, which may discourage deviant health behaviours [34], improve awareness of health and disease-related issues $[27,28]$ and improve overall well-being outcomes in poor communities [37].

Interventions aimed at strengthening social capital may thus reduce health inequalities. Pronyk and colleagues [5] found in their longitudinal study that social capital could be intentionally generated in relatively short programmatic time frames. They conducted an intervention in rural South Africa that combined group-based microfinance with participatory health education; within two years they had simultaneously promoted health, social capital, and economic development. This is in contrast to Putnam's proposal that the accumulation of social capital takes place only very slowly [26]. Public health practitioners and policy makers have recently turned to more comprehensive and participatory approaches to enhancing social capital, and thereby improving health outcomes [45]. Instead of adopting a top-down approach, policy makers increasingly work with community members to plan and implement health programmes. Farquhar and colleagues [46] found an association between 
Table 2 Ordinal logistic regression analyses ( $n=1,020$; Grahamstown 2007)

\begin{tabular}{|c|c|c|c|c|c|}
\hline Model & B & SE & Wald Z & $\mathbf{P}$ & OR \\
\hline Intercept $1 \leq 0$ & -6.061 & 0.589 & 105.177 & $\leq 0.001$ & 0.002 \\
\hline Intercept $2 \leq 1$ & -3.253 & 0.532 & 37.413 & $\leq 0.001$ & 0.039 \\
\hline $\begin{array}{l}\text { Intercept } 3 \leq 2 \\
\text { Intercept } 4 \leq 3\end{array}$ & $\begin{array}{c}-1.700 \\
0.987\end{array}$ & $\begin{array}{l}0.522 \\
0.522\end{array}$ & $\begin{array}{r}10.610 \\
3.502\end{array}$ & $\begin{array}{r}0.001 \\
0.061\end{array}$ & $\begin{array}{l}0.183 \\
2.683\end{array}$ \\
\hline \multicolumn{6}{|l|}{ Socio-economic conditions/resources } \\
\hline Married & 0.029 & 0.135 & 0.045 & 0.833 & 1.029 \\
\hline Male & -0.156 & 0.142 & 1.204 & 0.273 & 0.856 \\
\hline Age & -0.059 & 0.005 & 139.069 & $\leq 0.001$ & 0.942 \\
\hline Employment & 0.722 & 0.154 & 22.094 & $\leq 0.001$ & 2.058 \\
\hline Education (none or some primary) & -0.767 & 0.194 & 15.617 & $\leq 0.001$ & 0.464 \\
\hline Education (some secondary) & -0.085 & 0.165 & 0.269 & 0.604 & 0.919 \\
\hline Income & 0.001 & 0.035 & 0.000 & 0.985 & 1.001 \\
\hline Social capital & 0.501 & 0.119 & 17.845 & $\leq 0.001$ & 1.650 \\
\hline \multicolumn{6}{|l|}{ Housing quality } \\
\hline Leaky roof & -0.050 & 0.134 & 0.138 & 0.710 & \\
\hline Formally build house & -0.029 & 0.150 & 0.037 & 0.847 & 0.971 \\
\hline \multicolumn{6}{|l|}{ Neighbourhood quality } \\
\hline Crime in the area & 0.080 & 0.072 & 1.255 & 0.263 & 1.083 \\
\hline Residents get value for their rental rates & -0.156 & 0.088 & 3.186 & 0.074 & 0.856 \\
\hline \multicolumn{6}{|l|}{ Test } \\
\hline $\begin{array}{l}\text { Overall model evaluation } \\
\text { Wald test }\end{array}$ & & $\begin{array}{l}\text { Chi }^{2} \\
374.550\end{array}$ & $\begin{array}{l}d f \\
12\end{array}$ & $\begin{array}{r}P \\
\leq 0.001\end{array}$ & \\
\hline $\mathrm{R}^{2}$ Nagelkerke & $35.3 \%$ & & & & \\
\hline
\end{tabular}

Notes: reference group of the ordinal logistic model is excellent health (4). B = unstandardized regression coefficient.

health and social capital, and determined that increased social capital generated through community-based participatory interventions led to significantly improved health outcomes. Our findings also highlighted this effect of social capital.

This study revealed that unemployment, poor educational level and advanced age significantly contributed to poor health. With this article we wish to highlight the impacts of employment and education on health, and to suggest that health outcomes may be improved with interventions aimed at creating job opportunities, strengthening educational systems and promoting universal educational access. Health may be improved with interventions beyond the health sector such as grouplending microfinance schemes that could create employment and strengthen social capital at the same time $[5,19]$. Social capital could be further strengthened by creating meeting opportunities for neighbourhood residents [47]. Such policies may also improve a wide range of health issues by promoting healthy behaviour, disease awareness, and disease-preventive behaviour. In addition, health may be improved by strengthening educational systems and promoting universal educational access.

Some limitations must be considered when interpreting our study findings. First, the cross-sectional nature of the data limited our ability to draw causal inferences or determine the directionality of associations. Our establishment of significant associations is, however, an important step for further studies investigating directionality. Second, while Uphoff [48] distinguished between structural and cognitive dimensions of social capital, we only measured cognitive social capital. Cognitive social capital derives from individuals' perceptions of social capital resulting in norms, values and beliefs that contribute to cooperation. Structural social capital deals with individuals' actual behaviours and mainly takes the form of networks and associations.

\section{Conclusion}

Our study demonstrated that social capital, employment and education are significantly related to health in the low-income South African township of Rhini. These findings are important in understanding the struggles of the lowest socio-economic stratum. While existing health policies in South Africa emphasise disease treatment, our findings suggest that a greater emphasis on social environment, employment, and education could be more beneficial. We especially urge the designers of health-related interventions to consider the possible effects of social capital on health outcomes. We trust that these findings will be useful for policymakers, governments, municipalities, and organisations faced with the task of promoting good health. 


\section{Acknowledgements}

The project was funded by the South Africa Netherlands research Programme on Alternatives in Development (SANPAD). The views expressed in this paper are those of the authors.

\section{Authors' contributions}

AN participated in the design of the study and $\mathrm{JC}$ drafted the manuscript. $\mathrm{JC}$ and AN performed the statistical analysis. Both authors have read and approved the final version of the manuscript.

\section{Competing interests}

The authors declare that they have no competing interests.

Received: 28 May 2011 Accepted: 15 November 2011

Published: 15 November 2011

\section{References}

1. Cockerham WC: Medical Sociology New Yersey: Pearson Education International; 2010

2. WHO: Closing the gap in a generation: Health equity through action on the social determinants of health 2008 [http://whalibdoc.who.int/publications/ 2008/9789241563703_eng.pdf], Accessed December 2009.

3. Wilson J: Not so special after all? Daniels and the social determinants of health. J Med Ethics 2009, 35:3-6.

4. Idrovo AJ, Ruiz-Rodriguez M, Manzano-Patiño AP: Beyond the income inequality hypothesis and human health: a worldwide exploration. Revista de Saúde Pública 2010, 44(suppl 4):695-702.

5. Pronyk PM, Harpham T, Busza J, Phetla G, Morison LA, Hargreaves JR, KIM JC, Watts CH, Porter JD: Can social capital be intentionally generated? A randomized trial from rural South Africa. Soc Sci Med 2008, 67(suppl 10):1559-1570.

6. Harvey PW: Social determinants of health - why we continue to ignore them in the search for improved population health outcomes! Aust Health Rev 2006, 30(suppl 4):419-423.

7. Mohajer N, Earnest J: Widening the aim of health promotion to include the most disadvantaged: vulnerable adolescents and the social determinants of health. Health Educ Res 2010, 25(suppl 3):387-394.

8. Semenza JC: Strategies to intervene on social determinants of infectious diseases. Euro surveill 2010, 15(suppl 27), pii=19611.

9. Martin G, Bird P, Crichton C: Global health: where are our priorities? $\mathrm{Br}$ Med Bull 2009, 91:23-28.

10. World Health Organization: Closing the gap in a generation: health equity through action on the social determinants of health 2008 [http:/ whalibdoc. who.int/publications/2008/9789241563703_eng.pdf], Accessed 22 December 2009.

11. Kelly MP, Morgan A, Bonnefoy J, Butt J, Bergman V: The social determinants of health: developing an evidence base for political action (measurement and evidence knowledge network) Geneva, Switzerland: World Health Organisation; 2007

12. Setel PW, Macfarlane SB, Szreter S, Mikkelsen L, Jha P, Stout S, AbouZahr C A scandal of invisibility: making everyone count by counting everyone. Lancet 2007, 370:1569-1577.

13. Brassard P, Anderson KK, Menzies D, Schwartzman K, Macdonald ME: Knowledge and perceptions of tuberculosis among a sample of urban Aboriginal people. J Community Health 2008, 33:192-198.

14. Mangesho PE, Shayo E, Makunde WH, Keto GBS, Mandara CI, Kamugisha ML, Kilale AM, Ishengoma DR: Community knowledge, attitudes and practices towards tuberculosis and its treatment in Mpwapwa District, central Tanzania. Tanzan health res bull 2007, 9:38-43.

15. Subramanian SV, Kawachi I: Whose health is affected by income inequality? A multilevel interaction analysis of contemporaneous and lagged effects of state income inequality on individual self-rated health in the United States. Health Place 2006, 12:141-156.

16. Harling $G$, Ehrlich $R$, Myer $L$ : The social epidemiology of tuberculosis in South Africa: a multilevel analysis. Soc Sci Med 2008, 66(Suppl 2):492-505

17. Acevedo-Garcia D: Zip code-level risk factors for tuberculosis: neighborhood environment and residential segregation in New Jersey, 1985-1992. Am J Public Health 2006, 91(5):734-741.

18. McKay CM, Bell-Ellison BA, Wallace K, Ferron JM: A multilevel study of the associations between economic and social context, stage of adolescence, and physical activity and body mass index. Pediatrics 2007, 119:S84-S91.

19. Cramm JM, Koolman X, Møller V, Nieboer AP: Socio-economic status and self-reported tuberculosis: a multilevel analysis in a low-income township in the Eastern Cape South Africa. Journal of Public Health in Africa 2011, 2:e34:143-146.

20. Wen M, Browning CR, Cagney KA: Poverty, affluence, and income inequality: neighborhood economic structure and its implications for health. Soc Sci Med 2003, 57:843-860.

21. Rose R: How much does social capital add to individual health? A survey study of Russians. Soc Sci Med 2000, 51(9):1421-1435.

22. Hyyppä MT, Mäki J: Social participation and health in a community rich in stock of social capital. Health Educ Res 2003, 18(6):770-779.

23. Ziersch AM: Health implications of access to social capital: findings from an Australian study. Soc Sci Med 2005, 61(10):2119-2131.

24. Lochner K, Kawachi I, Brennan RT, Buka SL: Social capital and neighborhood mortality rates in Chicago. Soc Sci Med 2003, 56:1797-1805.

25. Requena F: Social capital, satisfaction, and quality of life in the workplace. Soc Indic Res 2003, 61(Suppl 3):331-360.

26. Putnam RD: Bowling Alone. The Collapse and Revival of American Community London: Simon and Schuster; 2000 .

27. Kawachi I, Berkman L: Social cohesion, social capital and health. In Social epidemioology. Edited by: Kawachi I, Berkman L. NewYork: Oxford University Press; 2000:174-190.

28. Rogers EM: Diffusion of innovations. 5 edition. New York: The Free Press; 2003.

29. Cramm JM, Nieboer AP: The relationship between (stigmatizing) ideas and the lay public preferences regarding tuberculosis treatment in the Eastern Cape, South Africa. Int J Equity Health 2011, 10(Suppl 1):2.

30. Møller V Erstad I, Cramm JM, Nieboer AP, Finkenflügel $H$, Radloff $S$, Ndoro T, Kwizera SA: Delays in presenting for TB treatment: Fears related to learning one is HIV positive. Afr J AIDS Res 2011, 10(Suppl 1):25-36.

31. Cramm JM, Finkenflügel HJM, Møller V, Nieboer AP: TB treatment initiation and adherence in a South African community influenced more by perceptions than by knowledge of tuberculosis. BMC Public Health 2010, 10(Suppl 72):1-8

32. Cramm JM, van Exel J, Møller V, Finkenflügel HJM: Patient views on determinants of compliance with tuberculosis treatment in the Eastern Cape, South Africa: an application of Q-methodology. Patient 2010, 3(Suppl 3):159-172.

33. Kim D, Kawachi I: U.S. state-level social capital and health related quality of life: multilevel evidence of main, mediating, and modifying effects. Ann Epidemiol 2007, 17(Suppl 4):258-269.

34. Poortinga W: Do health behaviors mediate the association between social capital and health? Prev Med 2006, 43:488-493.

35. Winkelman R: Unemployment, social capital, and subjective well-being. J Happiness Stud 2009, 10(Suppl 4):421-430.

36. Camfield L, Skevington SM: On subjective well-being and quality of life. J Health Psychol 2008, 13:764-775.

37. Cramm JM, Møller V, Nieboer AP: Improving subjective well-being of the poor in the Eastern Cape. J Health Psychol 2010, 15(7):1012-1019.

38. Forbes A, Wainwright SP: On the methodological, theoretical and philosophical context of health inequalities research: a critique. Soc Sci Med 2001, 53:801-816.

39. Møller V, Erstad I: Stigma associated with tuberculosis in a time of HIV/ AIDS: narratives from the Eastern Cape, South Africa. South African Review of Sociology 2007, 38:103-119.

40. Noble M, Barnes H, Wright G, Roberts B: Small area indices of multiple deprivation in South Africa. Soc Indic Res 2010, 95:281-297.

41. Møller V: Living in Rhini. A 2007 update on the 1999 social indicators report Institute of Social and Economic Research, Research Report Series No. 14; 2007.

42. Nemeth R: Respondent selection within the household - A modification of the Kish grid [http://www.math.uni-klu.ac.at/stat/Tagungen/Ossiach/Nemeth.pdf].

43. Lopez R: Income inequality and self-rated health in US metropolitan areas: A multi-level analysis. Soc Sci Med 2004, 59:2409-2419.

44. Baron-Epel O: Self-reported health. Encyclopedia of health and behavior. Edited by: Anderson NB. Sage CA, Thousand Oaks; 2004:.

45. Israel BA, Krieger J, Vlahov D, Ciske S, Foley M, Fortin P, Guzman JR, Lichtenstein R, McGranaghan R, Palermo A-G, Tang G: Challenges and facilitating factors in sustaining community-based participatory research 
partnerships: lessons learned from the Detroit, New York City and Seattle urban research centers. J Urban Health 2006, 83(Suppl 6).

46. Farquhar SA, Michael YL, Wiggins N: Building on history and social capital to create change in two urban communities. Am J Public Health 2005, 95(4):596-601.

47. Völker B, Flap H, Lindenberg S: When are neighborhoods communities? Community in Dutch neighborhoods. Eur Sociol Rev 2007, 23(Suppl 1):99-114.

48. Uphoff N, Wijayaratna CM: Demonstrated Benefits from Social Capital: The Productivity of Farmer Organizations in Gal Oya, Sri Lanka. World Dev 2000, 28:1875-1890.

doi:10.1186/1475-9276-10-51

Cite this article as: Cramm and Nieboer: The influence of social capital

and socio-economic conditions on self-rated health among residents

of an economically and health-deprived South African township.

International Journal for Equity in Health 2011 10:51.

\section{Submit your next manuscript to BioMed Central} and take full advantage of:

- Convenient online submission

- Thorough peer review

- No space constraints or color figure charges

- Immediate publication on acceptance

- Inclusion in PubMed, CAS, Scopus and Google Scholar

- Research which is freely available for redistribution

Submit your manuscript at www.biomedcentral.com/submit 